\title{
HALlAZGOS EN EL MAS BLANC (Penáguila)
}

\author{
FEDERICO RuBIO GOMIS
}

\section{EN DEUDA}

En junio de 1986 recibí una carta del Profesor Bendala, invitándome a participar con un artículo mío, en el homenaje que con motivo de la Jubilación de D. Gratiniano Nieto Gallo, se celebraría. Mi respuesta afirmativa fue inmediata, no sólo por un mínimo deber de gratitud hacia el que fue mi profesor, sino porque las relaciones humanas, de amistad y confianza entre mi persona y D. Gratiniano son muy superiores a lo normal entre alumno y maestro.

Además de todo lo que como "aprendiz» de arqueología tengo que agradecerle, fui honrado con su amistad y colaboración.

Nunca olvidaré las lecciones, que sin él querer, me impartió sobre caballerosidad, buen hacer y hombría ante la vida y los demás, lecciones que no fueron aprendidas en ninguna aula, sino en el roce diario y el trato habitual.

Gran parte de mi Memoria de Licenciatura y de mi Tesis Doctoral, se deben a él. Sin ir más lejos, me hizo el alto honor de prologar la publicación de esta última, publicación que desgraciadamente y por escasos días no podrá ver.

El gran golpe fue enterarme de su fallecimiento en los últimos días de julio.

Hace muy poco vio la luz un libro mío que publiqué dedicado a D. Gratiniano como mi maestro. Le mandé un ejemplar y poco después, con esa exquisita cortesía recibí su respuesta en la que fue nuestra última comunicación y en la que me indicaba «... lo que más satisface a quienes hemos hecho de la enseñanza nuestra dedicación fundamental, es el verse continuado en la obra y sobre todo en el recuerdo y en el afecto, de quienes han sido sus discípulos...".

La mayor satisfacción de este alumno es el poder decir públicamente que me honré con su trato y amistad.

D. Gratiniano, profesor, gracias.

\section{Situación Geográfica}

La llamada "Hoya de Alcoy» es una depresión que forma, entre otros, el río Serpis, en medio de una serie de cadenas montañosas. El fondo de este valle es 
una llanura más o menos quebrada por barrancos muy apta para la agricultura y lugar conocido por su gran fertilidad arqueológica. En medio, se alza una de las más altas cumbres del contorno, la Serreta, en cuya cima se sitúa el famoso yacimiento ibérico del mismo nombre.

Alrededor de esta ciudad ibérica se formó un área de influencia, con una serie de hallazgos dispersos, en un principio y mientras la ciudad existió, en clara dependencia y relación con ella; posteriormente hacia el cambio de Era, cuando los habitantes de la Serreta se dispersan por los llanos de alrededor, se forman una serie de «villae» o pequeños núcleos de población que forman la continuidad del hábitat en la zona.

Varios son estos yacimientos descubiertos hasta ahora, el Carrascalet, la Condomina, Las Puntas, La Pedrera, Ull del Moro, Mas Blanc y el dudoso del Bancal de la Corona, por citar sólo aquéllos cronológicamente más próximos a la etapa que estamos tratando.

Precisamente es el Mas Blanc sobre el que vamos a centrar este estudio.

\section{El yacimiento}

Básicamente se trata de una serie de hallazgos sueltos y superficiales y de la excavación de una tumba realizadas en los terrenos situados en los alrededores del Mas Blanc, en el llamado "Pla del Llop», en el linde entre los términos municipales de Penáguila y Benifallim, a unos 1.750 metros al N.O. de esta última población (fig. 1).

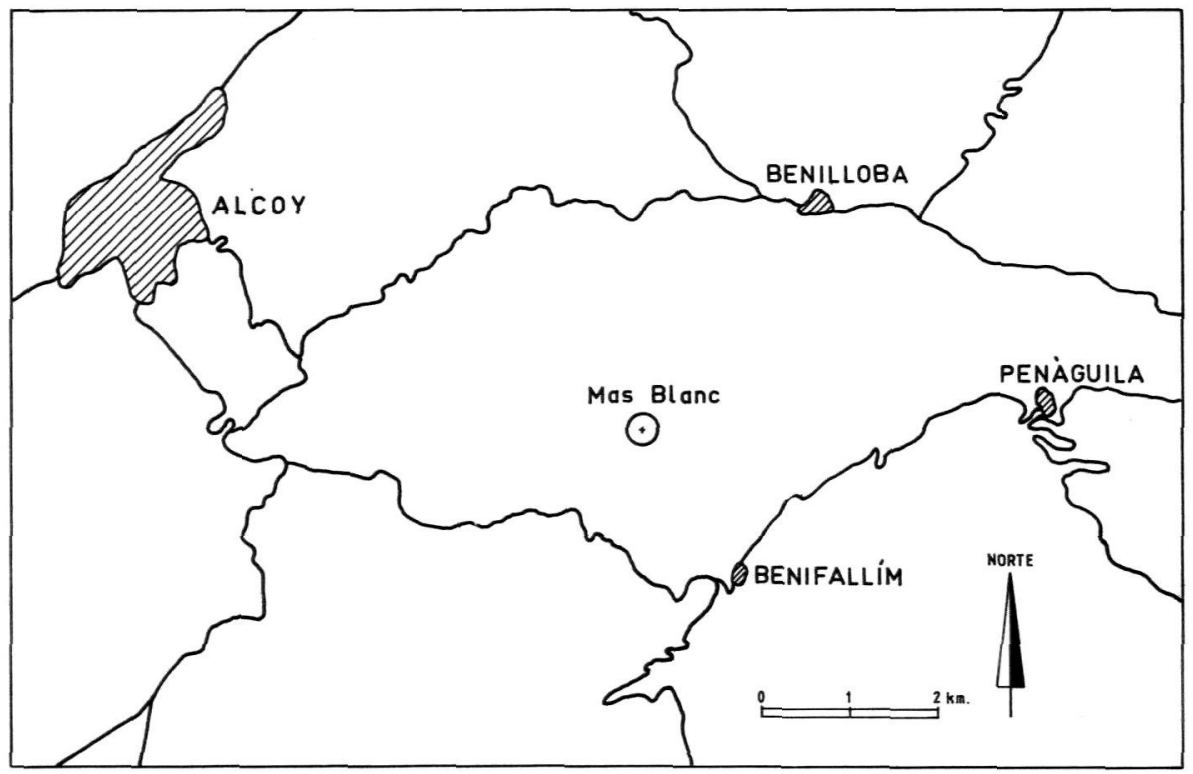

FIG. 1.-Plano de Situación del Mas Blanc. 
Ya D. Camilo Visedo Moltó, por amistad con el propietario de la masía, hacía frecuentes visitas al lugar, pero la excavación de la tumba la realizó D. Vicente Pascual el 24 de agosto de 1952.

Juan Faus, en prospecciones realizadas en septiembre de 1971 y febrero de 1972, recogió los materiales que damos como de superficie.

\section{Los materiales de superficie}

2.436. - Fragmento de cerámica a torno, muy tosca, con una incisión gruesa y profunda, realizada sobre la pasta aún tierna, pero retocada posteriormente, en forma de Y. Pasta gris en el interior y ocre oscuro en el exterior. Textura muy rugosa. Long. $8 \mathrm{~cm}$. (fig. 2).

2.440. - Lote de tres fragmentos del galbo de cerámica pintada. Pasta ocre. Decoración color siena. Uno con decoración de simples bandas, otro con parte de un grupo de círculos concéntricos y puntos y el tercero con una banda y líneas oblícuas (fig. 2).

9.369. - Lote de once fragmentos del galbo de cerámica ibérica. Dos de ellos con decoración de bandas. Todos de pasta ocre.

\section{La tumba}

Durante una prospección realizada el 8 de febrero de 1952, D. Vicente Pascual localizó la existencia de una tumba que no excavó hasta el mes de agosto de ese mismo año.

De la superficie del terreno, bajo el que estaba situada la tumba y recogidos en la prospección de febrero que sirvió para localizarla, proceden los siguientes materiales:

9.367. - Fragmento del borde de un vaso de terra sigillata clara D. "Barniz» ligero y poco brillante. Long.: $2,8 \mathrm{~cm}$. (fig. 2).

9.368. - Fragmento del borde de un vaso de terra sigillata, como el anterior. "Barniz» ligero y poco brillante. Long.: 3,2 cms. (fig. 2).

\section{Descripción de la tumba}

No son muchos los datos sobre la tumba que poseemos.

Era una de las típicas sepulturas romanas con techo «a dos aguas», de tejas planas.

Tenía al menos tres tejas en cada lado, pero desconocemos si estaba cerrada por la parte superior e inferior y con qué.

Un extremo de la sepultura estaba alterada y aunque D. Vicente Pascual no nos indica cuál, supongo que se trataría del extremo de las piernas, pues mientras que se cita el hallazgo de los huesos de las extremidades superiores, algunas de las vértebras y él cŕaneo, no se hace mención de los huesos largos de las piernas. 

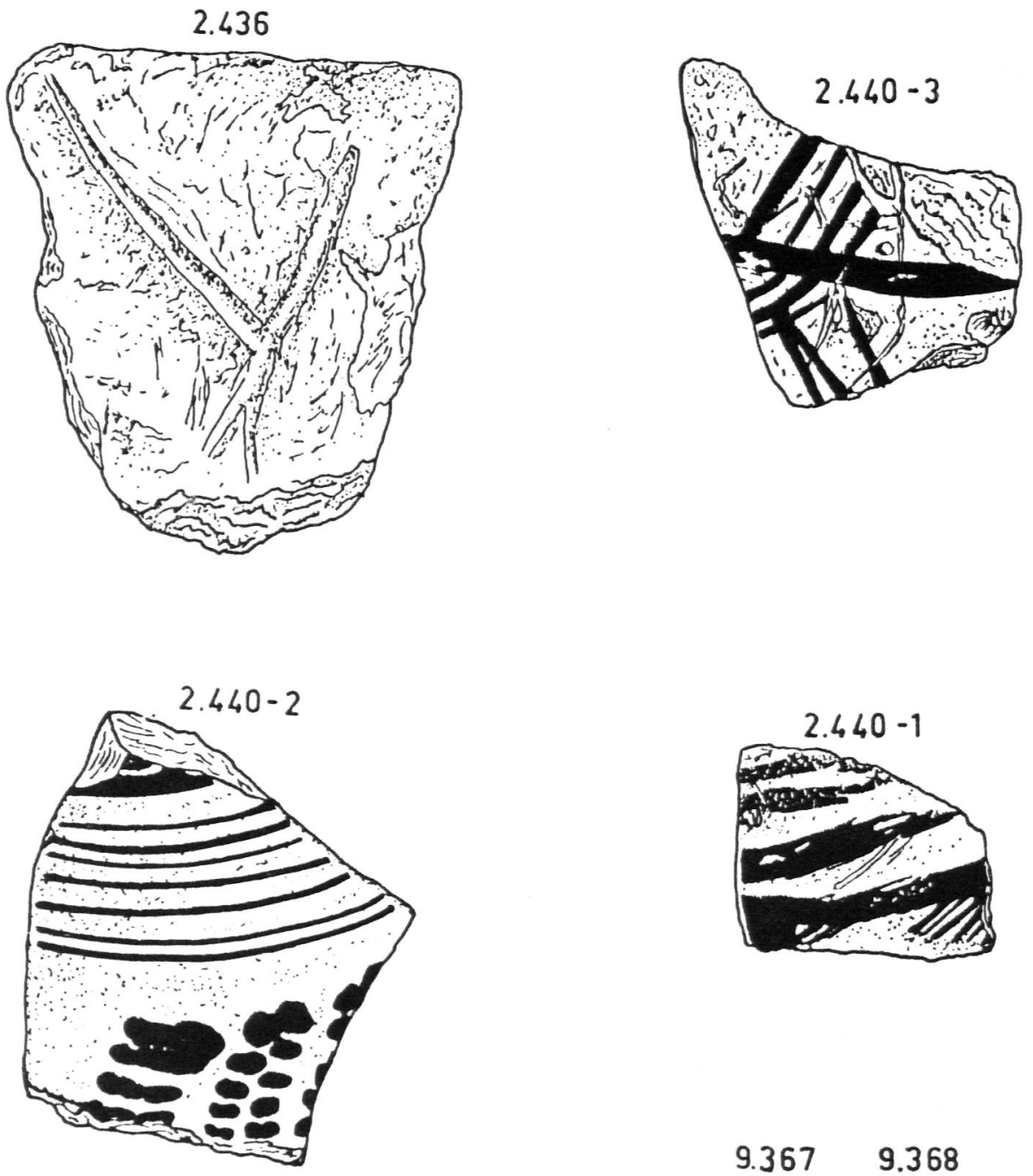

FIG. 2.-Materiales de superficie del Mas Blanc. 
El ajuar estaba compuesto por los siguientes objetos:

2.437. - Aguja de bronce con cabeza cónica de cazoleta que contiene una gota de pasta vítrea blanca. Long.: 6,4 cm. (fig. 3).

2.438. - Idem a la anterior partida en dos fragmentos. Long.: total $4,7 \mathrm{~cm}$. (fig. 3).

2.439. - Fragmento de la base de un plato de terra sigillata clara D. Barniz rojo naranja brillante sólo por el interior. Long.: $8 \mathrm{~cm}$. (fig. 3).

2.441. - Concha de "cardium edule».

2.442. - Lasca de sílex grisáceo con un borde con retoque denticular Long.: $3,4 \mathrm{~cm}$.

2.443. - Fragmento del borde de un vaso de vídrio verdoso en buen estado de conservación. Long.: 4,3 cm. (fig. 3).

2.206. - Varios restos de huesos humanos, sobre todo de un cráneo incompleto.

\section{Conclusiones y cronología}

Del material recogido en superficie se puede determinar un hábitat que podría abarcar desde el siglo III a. C. hasta el IV d. C.

La cerámica ibérica no tiene una cronología concreta dentro de la cultura ibérica, puesto que la decoración geométrica se produce a lo largo de toda ella y lo pequeño de los fragmentos no me permite determinar mayor precisión cronológica, puesto que no puedo reconstruir ni la forma del vaso ni decoración.

El fragmento con la incisión puede tratarse de una letra ibérica, concretamente el signo $\mathrm{Y}$, el único cuyo valor fonético es desconocido, en cuyo caso no podría remontar el siglo III a. C.

Tanto la cerámica de superficie de la tumba como la del anterior se pueden fechar perfectamente dentro del siglo IV d. C., fecha que coincide perfectamente con el fragmento de vidrio y las agujas con cabeza decorada de cabujón.

Paralelos cercanos de esta agujas tenemos en las Necrópolis de Huerta Mayor (Alcoy) del siglo II al V de les Jovades (Cocentaina), a lo que Llobregat (1) da una fecha de la segunda mitad del siglo VI a la primera del VII, fecha en mi opinión muy alta, pues creo que dichas tumbas serán del siglo $\mathrm{V}$.

Lo corriente de este tipo de agujas no merece una relación completa de hallazgos peninsulares, sólo recalcar su presencia siempre en tumbas tardorromanas, cuyo principio podemos suponer en el siglo III, pero cuyo final no está tan claro, pues según autores pueden llegar al siglo VII, aunque personalmente no creo que sobrepasen el siglo $\mathrm{V}$.

El cadáver no debió tener ninguna caja que lo guardara, con total ausencia de otros elementos de ornato personal.

Quiero destacar, que hasta el presente no conozco ningún hallazgo de este tipo de agujas fuera de necrópolis, lo que parece conferirle un carácter propio del atuendo personal de los difuntos y no ser un objeto de uso diario.

Alcoy, agosto de 1986

(1) Llobregat, E. A.: Enterramientos de época romana tardía en Cocentaina (Alicante). Segovia y la Arqueología Romana (1976), págs. 257-264. Barcelona, 1977. 

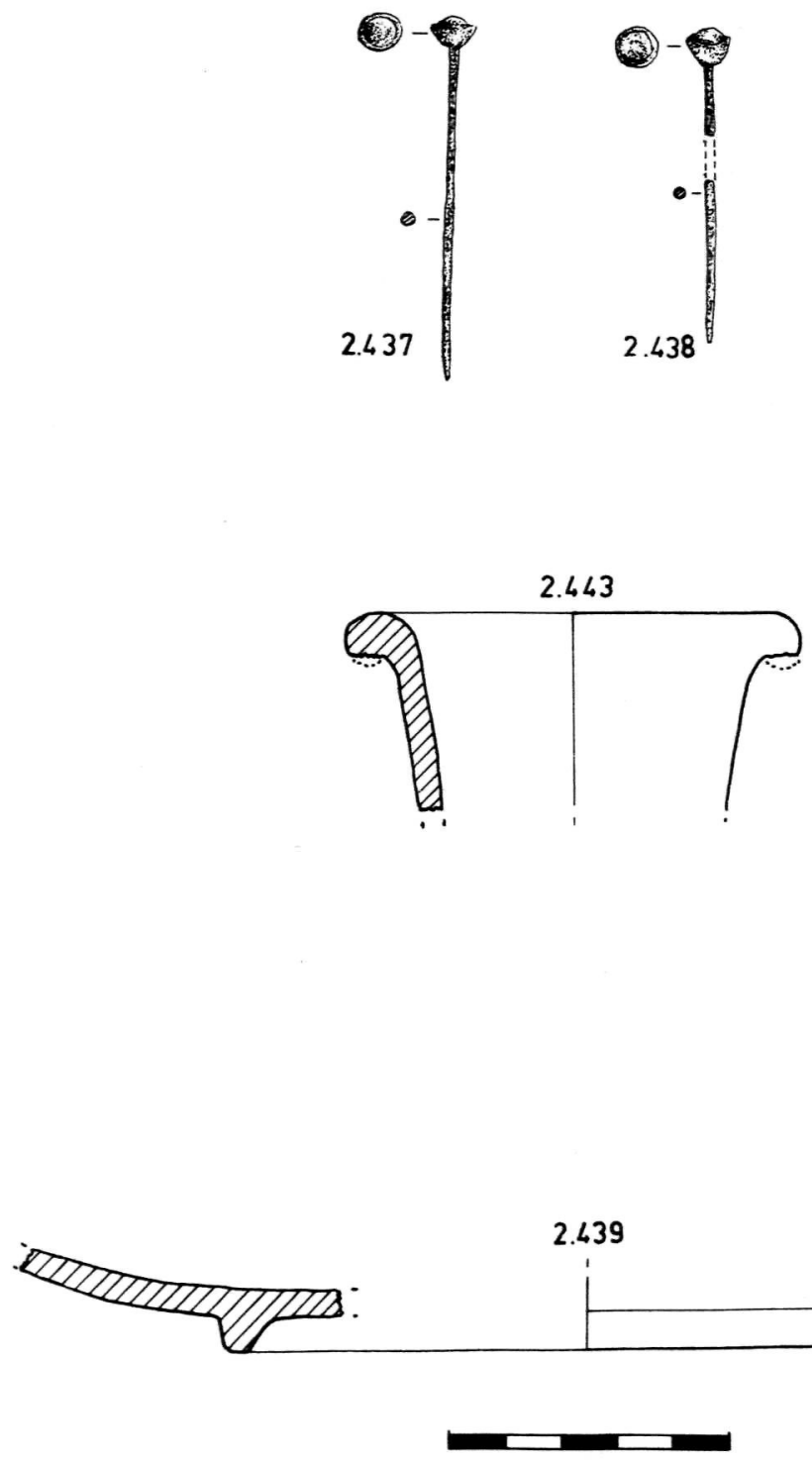

FIG. 3.-Ajuar de la tumba. 